\title{
Economic analysis of acupuncture for migraine prophylaxis
}

This article was published in the following Dove Press journal:

Neuropsychiatric Disease and Treatment

\author{
Jitka Pokladnikova ${ }^{1,2}$ \\ Petra Maresova ${ }^{3}$ \\ Josef Dolejs ${ }^{3}$ \\ A-La Park ${ }^{4}$ \\ Bo Wang ${ }^{5}$ \\ Xin Guan ${ }^{5}$ \\ Frantisek Musil'
}

'Czech-Chinese Centre for Traditional Chinese Medicine, University Hospital in Hradec Kralove, Hradec Kralove, Czech Republic; ${ }^{2}$ Faculty of Pharmacy in Hradec Kralove, Charles University, Hradec Kralove, Czech Republic; ${ }^{3}$ Faculty of Informatics and Management, University of Hradec Kralove, Hradec Kralove, Czech Republic; ${ }^{4}$ Personal Social Services Research Unit, Department of Health Policy, London School of Economics and Political Science, London, UK; ${ }^{5}$ Shuguang Hospital Affiliated to Shanghai University of Traditional Chinese Medicine, Shanghai, China

Correspondence: Jitka Pokladnikova Czech-Chinese Centre for Traditional Chinese Medicine, University Hospital in Hradec Kralove, Sokolska 58I, Hradec Kralove 50005, Czech Republic

Tel +420728585562

Fax +42049583200 I

Email jitka.pokladnikova@faf.cuni.cz
Background: Acupuncture has become a viable option for migraine prophylaxis in Europe; however, despite its wide use, more data on the short- and long-term cost-effectiveness are needed when considering the perspectives of a paying third-party, the patient, and of society in general. The aim was to evaluate the cost and effectiveness of adjuvant acupuncture to pharmacologic treatment vs pharmacologic treatment alone in migraine patients after a 3-month acupuncture course and a 6-month follow-up from all perspectives.

Methods: The study involved an open-label randomized clinical trial of patients receiving acupuncture $(n=42)$, and a waiting list control group $(n=44)$. The number of migraine days during the last 28 days, as well as direct and indirect costs were considered. The trial was registered under DRKS00009803.

Results: The total cost per patient reached $€ 696$ vs $€ 285$ after 3 months of acupuncture and $€ 66$ vs $€ 132$ in the acupuncture and control groups after a 6-month follow-up, respectively ( $P=0.071)$ The trends observed in effectiveness and costs from all perspectives are discussed.

Conclusion: The inclusion of acupuncture in health care results beneficial mainly for its observed trend in reduced losses of productivity and income, with the latter often exceeding the costs of acupuncture treatment. As such, acupuncture may be recommended as an adjuvant treatment in migraine prophylaxis to standard pharmacotherapy.

Keywords: acupuncture, cost, effectiveness, migraine, prophylaxis, Traditional Chinese Medicine

\section{Introduction}

Migraine is classified within a group of highly prevalent brain disorders with a calculated cost of $€ 662$ per migraineur and representing the highest proportion of indirect health care costs, accounting for $87 \%$ of overall costs in comparison with other conditions. ${ }^{1,2}$ In Europe, one-third of the population presents at least one brain disorder, including migraine, resulting in an overall cost of 798 billion euro per year (2010). ${ }^{2}$ Migraine-associated disability often results in reduced social activities and work capacity, for example, in the UK some 25 million working/school-days are lost every year because of migraine alone. ${ }^{3}$ Still, headaches might often be overlooked, by both the lay public and some health care professionals, as a minor complaint and its impacts on physical, emotional, social health, as well as economic development, may not always be fully acknowledged. Further, brain disorders in general are identified as a major health economic challenge in Europe, calling for wider attention on behalf of the health authorities and national governments, as well as more funding for brain research. ${ }^{2}$

A previous meta-analysis proved that acupuncture could become a viable prophylactic treatment option for frequent or uncontrolled migraine, or for migraineurs 
experiencing drug side effects. ${ }^{4,5}$ Acupuncture is seemingly superior to pharmacologic treatments in terms of the occurrence of fewer side effects and potential long-term effectiveness after its discontinuation. ${ }^{6-8}$ There is also some evidence suggesting that the introduction of acupuncture to an existing pharmacologic treatment can result in a reduced economic impact due to decreased use of medications, number of sickness absence, and medical review appointments. ${ }^{9}$ Despite the evidence for the potential cost-effectiveness of acupuncture in chronic pain management, such as headache, osteoarthritis, and lower back pain, additional data on the longterm cost-effectiveness of acupuncture are needed. ${ }^{8-11}$ Our comparative study is the first economic analysis comparing acupuncture with a standard pharmacologic treatment in the Czech Republic. The aim of the study was to evaluate the effectiveness and cost of acupuncture treatment in patients with migraine after a 3-month course of acupuncture and 6-month follow-up from three perspectives: a third-party payer, the patient, and society.

\section{Methods}

\section{Experimental design}

The current study is based on an open-label randomized clinical trial (October 2015 to April 2017), taking place at the Czech-Chinese Centre for Traditional Chinese Medicine in the University Hospital Hradec Kralove. The patients were randomly assigned to either acupuncture (AG) or a waiting list control group (CG). During a 12-week therapeutic period, acupuncture treatment was administered 14 times using the semi-standardized therapeutic acupuncture protocol. Patients in both groups were administered with the standard pharmacologic treatment (prophylactic medication and analgesics as needed) following the appropriate guidelines. ${ }^{12}$ The design of the trial including flow diagram and intervention has been described in detail elsewhere. ${ }^{13}$

\section{Patients}

Patients aged between 18 and 70 years, attending the Neurology Outpatient Clinic at the University Hospital Hradec Kralove, and with a clinical history of migraine of at least 12 months and a minimum of 4 days of migraine in 4 weeks, were enrolled in the study. All patients were diagnosed with migraine by board-certified neurologists according to the criteria set by the International Classification of Headache Disorders. ${ }^{14}$ A written informed consent was obtained from all patients. The study was approved by the Ethical Committee of the University Hospital Hradec Kralove, registered under the code DRKS00009803.

\section{Outcomes}

The primary outcome was to compare the cost of acupuncture in patients with migraine after a 3-month course of treatment (T12) and a 6-month follow-up (T36) from three perspectives: a paying third party, the patient, and society in general.

\section{Effectiveness}

The effectiveness of the treatment was evaluated according to a previous study ${ }^{13}$, and the first parameter evaluated the number of migraine days in the last 4 weeks before randomization (baseline period) (T0), and at 12 (T12) and 36 (T36) weeks after randomization. A second parameter evaluated the reduction in relief medication use, migraine intensity and duration, and the number of patients with reduced migraine frequency ( $\geq 50 \%$ ) over a 4 -week period. Specific quality of life using the Migraine Disability Assessment (MIDAS) was also recorded. ${ }^{15}$

\section{Costs}

The present study employs the methodology established by Drummond, ${ }^{16}$ dividing the costs into direct and indirect categories. The former includes variable and fixed costs, whereas the latter includes the costs incurred by the patients and their families. In this regard, the psychological costs are also of a similar nature and therefore not negligible; however, these are not the subject of this paper as neither are the costs associated with hospitalization. Loss of productivity was calculated on the basis of "Human Capital Approach". ${ }^{17}$ Direct and indirect costs were not discounted as the intervention period was less than 1 year. Prices of individual items are shown in Table 1.

In the discussion section a further division of costs is used, namely from a third party payer's, a patient's, and societal perspectives. ${ }^{18,19}$ The individual items under examination using the categories of direct and indirect $\operatorname{costs}^{16,20}$ were set as

Table I Unit cost

\begin{tabular}{l|l}
\hline Type of costs & $€^{\mathrm{a}}$ \\
\hline Treatment & \\
Acupuncture (cost out-of-pocket) & \\
$\quad$ Acupuncture package (an initial visit, five & 166.0 \\
acupuncture sessions, and a check-up visit) & \\
$\quad$ Acupuncture follow-up session & 16.6 \\
Medication, package (reimbursement/co-payment) & \\
Health care service, unit & $-c$ \\
Productivity/income loss, working day & 0.04 \\
Travels, km & 24.52 \\
\hline
\end{tabular}

Notes: ${ }^{\text {a }}$ EUR $=27.05 \mathrm{CZK}$. ${ }^{\text {bPescription }}$ and over-the-counter drugs were reimbursed based on the Czech National Drug Price List of $2015 / 2016^{23}$ and priced at the average price calculated from the actual retail prices obtained from a sample of retail and hospital pharmacies in the study location in 2015/2016. 'The unit cost depends on the type of medication and so an average price cannot be established. 
follows: direct medical costs (medications, outpatient visits, acupuncture visits, emergency visits, adverse drug reactions), nonmedical direct costs (travel costs), and indirect costs (loss of income, productivity lost) (Table 2). Within the framework of the second parameter for costs examination, the individual groups are a third-party payer (outpatient visits, medication reimbursement, acupuncture visits, emergency visits, and adverse drug reactions), the patient's perspective (medication-drugs' surcharge, over-the-counter (OTC) drugs, travel costs, loss of income, acupuncture visits), and the societal perspective (productivity lost).

The health care costs were calculated by multiplying the number of units for intervention by the unit's price. The costs of drugs were calculated on a consumption basis expressed as defined daily doses (DDDs) and the price per DDD. ${ }^{21}$ Travel expenses by the patients were calculated as the product of the number of visits to the physician and the price of each visit. Loss of income was recorded as a result of deterioration of symptoms and days off owing to an appointment with the physician.

\section{Resource use}

The information concerning demographics data of the patient's clinical condition, comorbidities, medications, physician's time, and costs of health care services (visits to physicians, visits to emergency department [ED], hospitalization) were obtained from electronic patient record system at the Faculty Hospital in Hradec Králové.

The number of units for intervention and their unit cost were based on current legislation of the Czech Republic for

Table 2 Direct and indirect costs

\begin{tabular}{|c|c|c|}
\hline \multicolumn{2}{|l|}{ Direct costs } & \multirow[t]{2}{*}{ Indirect costs } \\
\hline Medical & Nonmedical & \\
\hline $\begin{array}{l}\text { Medication } \\
\text { Outpatient visits } \\
\text { Acupuncture visits } \\
\text { Emergency visits } \\
\text { Adverse drug reactions }\end{array}$ & Travel costs & $\begin{array}{l}\text { Loss of income } \\
\text { Productivity loss }\end{array}$ \\
\hline Paying third party & $\begin{array}{l}\text { Patient's } \\
\text { perspective }\end{array}$ & $\begin{array}{l}\text { Society's } \\
\text { perspective }\end{array}$ \\
\hline $\begin{array}{l}\text { Outpatient visits } \\
\text { Medication reimbursement } \\
\text { Acupuncture visits } \\
\text { Emergency visits } \\
\text { Adverse drug reactions }\end{array}$ & $\begin{array}{l}\text { Medication (drug } \\
\text { surcharge, over-the- } \\
\text { counter drugs) } \\
\text { Travel costs } \\
\text { Loss of income } \\
\text { Acupuncture visits }\end{array}$ & Productivity loss \\
\hline
\end{tabular}

Note: Costs dividing data from Drummond et al $^{16}$ and Maresova et al. ${ }^{20}$
2015/2016. ${ }^{22}$ Drug reimbursements were determined according to the Numerical Index 2015/2016. ${ }^{23}$ However, there is no available source of information concerning the selling price of drugs in the Czech Republic; therefore, the selling price of drugs and OTC drugs were expressed as a mean obtained from a sample of selected hospital and community pharmacies in a given locality (2015/2016). The following data were collected from patients in the form of questionnaires: use of OTC drugs, visits to ED, hospitalization, sick leave, days off from work or school, and time spent at the physician's office, including transit. Travel expenses were calculated based on the distance between the physician's office and the patient's place of residence and the price of fuel per kilometer. ${ }^{24}$ Productivity lost was expressed by the number of days off per employee, evaluating each day by the proportional mean gross pay for the year 2015/2016 in the Czech Republic and the number of working days in a year according to data available by the Czech Statistical Office in the Czech Republic. ${ }^{25}$ The costs were expressed in euros using purchasing power parity for the $2015 / 2016$ year. ${ }^{26}$

\section{Statistical analysis}

The statistical analyses of individual costs were performed using the R Project for Statistical Computing v3.3.3, and MS Excel 2016 was used for data manipulation. A $P$-value $\leq 0.05$ was considered significant in all cases and the number of iterations was of 1,000 in the bootstrap method. At first, normality was tested in 42 patients with acupuncture and in 44 patients in the CG for individual item costs. Normality was tested using the Shapiro-Wilk normality test (namely, the function "shapiro.test" was used). Normality was rejected in all cases $(P<0.05)$, and, consequently, to take account of the skewed distributions of the costs, the bootstrap method (namely, the package "boot" version 2017.2 and the function "boot" were used) was used with $95 \%$ CIs of the means. ${ }^{27}$ The null hypothesis, meaning equal in the $\mathrm{AG}$ and the $\mathrm{CG}$, was tested against the alternative hypothesis stating that the costs are lower in the AG using the bootstrap method. Consequently, the resulting $P$-values were one tailed, and the package "boot" version 2017.2 was used in the calculations.

The cost of an acupuncture session was varied from $€ 11$ to $€ 35$ for each patient, and all other costs were consistent in the analysis.

\section{Results}

\section{Sample characteristics}

A total of 91 patients were enrolled in the study, and the flow diagram was reported elsewhere. ${ }^{13}$ There were no significant 
Table 3 Baseline patient characteristics

\begin{tabular}{|c|c|c|}
\hline Characteristics & $\begin{array}{l}\text { Acupuncture } \\
\text { group } \\
\mathrm{N}=42\end{array}$ & $\begin{array}{l}\text { Control } \\
\text { group } \\
\mathrm{N}=44\end{array}$ \\
\hline \multicolumn{3}{|l|}{ Age (years) } \\
\hline Mean (SD) & $45.6(12.8)$ & $46.5(10.3)$ \\
\hline Median & 47 & 47.5 \\
\hline Female, n (\%) & $37(88)$ & $39(89)$ \\
\hline Positive family history of migraine, $n(\%)$ & $24(57)$ & $29(66)$ \\
\hline \multicolumn{3}{|l|}{ Duration of migraine (years) } \\
\hline Mean (SD) & $26.9(12.9)$ & $23.0(14.1)$ \\
\hline Median & 27.5 & 20.0 \\
\hline Comorbidity, n (\%) & $23(54.8)$ & $23(52.3)$ \\
\hline Smokers, n (\%) & $9(2 \mathrm{I})$ & $5(I I)$ \\
\hline \multicolumn{3}{|l|}{ Migraine days } \\
\hline Frequency (no. per month) & $11.97(6.6)$ & I2.I (9.2) \\
\hline Duration (hours) & $12.2(15.3)$ & $10(11.4)$ \\
\hline Intensity, VAS (mm) & $5.2(1.3)$ & $5.4(1.8)$ \\
\hline \multicolumn{3}{|l|}{ Drug consumption (ATC/DDD) } \\
\hline Rescue medication, mean (SD) & $14.8(\mid 4.3)$ & II.5 (II.8) \\
\hline Prophylactic medication, mean (SD) & $9.6(11.9)$ & $7.2(11.9)$ \\
\hline Migraine attack (no per month) & $6.4(2.4)$ & $6.0(2.7)$ \\
\hline Migraine disability assessment score & $48.9(38.1)$ & $52.9(31.9)$ \\
\hline $\begin{array}{l}\text { Employees (during working hours), } \\
\mathrm{n}(\%)\end{array}$ & $17(40.5)$ & $23(52.3)$ \\
\hline Employees (unpaid hours), n (\%) & $3(7.1)$ & $5(\mathrm{II} .4)$ \\
\hline $\begin{array}{l}\text { Place of residency (local patients), } \\
n(\%)\end{array}$ & $9(21.4)$ & $16(36.4)$ \\
\hline $\begin{array}{l}\text { Employees (during working hours), } \\
\mathrm{n}(\%)\end{array}$ & $17(40.5)$ & $23(52.3)$ \\
\hline
\end{tabular}

Abbreviations: ATC/DDD, anatomical therapeutic classification/defined daily dose; VAS, visual analog scale.

differences between groups when concerning the baseline characteristics (Table 3 ).

A significant reduction in the number of migraine days per 4 weeks was reached at the end of the intervention $(\Delta-2.0 ; 95 \% \mathrm{CI}:-4$ to -1$)$ as well as at the 6-month follow up $(\Delta-4.0 ; 95 \% \mathrm{CI}:-6$ to -2$)$. A significant percentage of responders to treatment was noted in the $\mathrm{AG}$ vs $\mathrm{CG}$ at the end of the intervention $(50 \%$ vs $27 \% ; P<0.05)$ as well as at the 6-month follow-up ( $81 \%$ vs $36 \% ; P<0.001)$. The AG showed a notable reduction in the intake of symptomatic medication compared with the $\mathrm{CG}$ at the end of acupuncture ( $\Delta-2.7 ; 95 \% \mathrm{CI}:-5.2$ to -0.7$)$ and the 6-month follow-up $(\Delta-3.0 ; 95 \% \mathrm{CI}:-5.8$ to -0.7$)$. Disease-specific quality-oflife score was improved in both groups at both time points, yet a reduction in the MIDAS scores remained significant only in the AG at the 6-month follow-up. Nevertheless, there was a significant difference between the number of patients with mild (grades I and II; mean score 0-10) vs moderate and severe disability (grades III and VI; mean score $>10$ ) before and after the intervention, as well as in the follow-up, in favor of the AG. ${ }^{13}$

\section{Use of health care services}

The average number of visits to the physician's office remained similar in both groups at both time points (Table 4); on average, patients in the AG visited their acupuncturist 13.5 times (SD 0.7). The number of migraine-related visits to the ED was significantly lower in the AG during acupuncture treatment when compared to the $\mathrm{CG}$, although no between-group differences were found (T0: 0.4 vs T12: 0.1; $P=0.012$ ) (Table 4). Also, patients in the AG experienced fewer drug side effects compared to the $C G$ over the course of acupuncture treatment; yet, the reduction did not last till the 6-month follow-up (Table 4). No serious adverse effects were reported following acupuncture treatment.

\section{Costs}

The overall mean cost per patient from all the three perspectives is given in Table 5. Neither of the evaluation periods for AG and CG showed a significant difference in the cost components; nevertheless, the absolute amounts of changes in some costs are still interesting. The direct costs were always lower in the AG vs CG; however, at 3 months, AG costs were higher than those of CG ( $€ 506.4$ vs $€ 64.4)$ - when the costs associated with acupuncture visits and traveling were included. When these costs were not considered, however, the direct costs were lower in the AG.

At a 6-month follow-up, the direct and indirect total costs were lower in the AG, where direct costs were lower by $€ 20$ and the indirect costs by $€ 46$.

It is worth mentioning that the costs changed over time for each group. Within the AG, there was a gradual decrease in the loss of income (T0: $€ 6$, T12: $€ 14.0$, T36: $€ 3.7)$ and productivity loss (T0: €128.3, T12: €123.3, T36: €10.2). Overall, a decrease in indirect costs could be observed in $\mathrm{AG}$, from $€ 134.3$ at the baseline to $€ 13.9$ at the 6-month follow-up. Direct costs within the AG were inevitably higher during the intervention period and then dropped (T0: $€ 38.1$, T12: €506.4, T36: €51.7). Within the AG direct costs show a gradual increment in all time periods (T0: $€ 39.4, \mathrm{~T} 12$ : $€ 64.4$, T36: €71.9); further, the absolute comparison of AG and CG at the 6-month follow-up period shows that the direct costs are higher by $€ 20.2$ in the $A G$.

\section{Paying third-party perspective}

From a third-party payer's perspective, there were no significant changes between both groups. However, there were lower costs for medication reimbursement in AG during the acupuncture treatment period ( $€ 25.6$ per person) and at the 6-month follow-up (€29.3). Outpatient and emergency 
Table 4 Mean use of resources during a 3-month acupuncture treatment and a 6-month follow-up

\begin{tabular}{|c|c|c|c|c|c|c|c|}
\hline \multirow[b]{2}{*}{ Baseline year } & \multicolumn{3}{|c|}{ Acupuncture group $N=42$} & \multicolumn{3}{|c|}{ Control group $N=44$} & \multirow[t]{2}{*}{$P$-value } \\
\hline & $\mathbf{N}$ & Mean & SD & $\mathbf{N}$ & Mean & SD & \\
\hline Rescue/prophylactic medication (ATC/DDD) ${ }^{\mathrm{a}}$ & 42 & $14.8 / 9.6$ & $(\mid 4.3 / 11.9)$ & 44 & $11.5 / 7.2$ & $(I I .8 / 11.9)$ & NS \\
\hline Outpatient visits, $n$ & 42 & 1.0 & 0.7 & 44 & 1.0 & 0.8 & NS \\
\hline Productivity loss, working days & 42 & 0.1 & 0.1 & 44 & 0.1 & 0.2 & NS \\
\hline Loss of income, unpaid working days & 42 & 0.0 & 0.1 & 44 & 0.0 & 0.1 & NS \\
\hline Emergency visits & 42 & 0.4 & 0.5 & 42 & 0.3 & 0.6 & NS \\
\hline Hospitalization & 40 & 0.0 & 0.0 & 41 & 0.0 & 0.0 & NS \\
\hline Adverse drug reactions, $\mathrm{n}(\%)$ & 41 & 9 & $(22.0)$ & 41 & 10 & $(24.4)$ & NS \\
\hline \multicolumn{8}{|l|}{ Acupuncture treatment ( 3 months) } \\
\hline Rescue medication (ATC/DDD) ${ }^{\mathrm{a}}$ & 42 & 26.1 & 41.4 & 42 & 26.8 & 27.5 & NS \\
\hline Acupuncture visits, $n$ & 42 & 13.5 & 0.7 & & & & \\
\hline Productivity loss, working days & 42 & 0.8 & 1.4 & & & & \\
\hline Loss of income, unpaid working days & 42 & 0.3 & 0.9 & & & & \\
\hline Outpatient visits, $\mathrm{n}$ & 42 & 1.0 & 1.0 & 42 & 1.0 & 0.9 & NS \\
\hline Productivity loss, working days & 42 & 0.1 & 0.2 & 42 & 0.1 & 0.1 & NS \\
\hline Loss of income, unpaid working days & 42 & 0.0 & 0.1 & 42 & 0.0 & 0.1 & NS \\
\hline Emergency visits & 42 & $0.1 *$ & 0.4 & 42 & 0.2 & 0.5 & NS \\
\hline Hospitalization & 42 & 0.0 & 0.0 & 42 & 0.0 & 0.0 & NS \\
\hline Adverse drug reactions, $\mathrm{n}(\%)$ & 42 & 2 & $(4.8)$ & 40 & 6 & $(\mid 5.0)$ & NS \\
\hline \multicolumn{8}{|l|}{ 6-month follow-up } \\
\hline Rescue medication (ATC/DDD) ${ }^{\mathrm{a}}$ & 40 & 26.6 & 50.8 & 41 & 28.4 & 31.9 & NS \\
\hline Outpatient visits, $\mathrm{n}$ & 40 & 0.7 & 0.7 & 41 & 1.0 & 1.1 & NS \\
\hline Productivity loss, working days & 40 & $0.0^{*}$ & 0.1 & 41 & 0.1 & 0.2 & NS \\
\hline Loss of income, unpaid working days & 40 & 0.0 & 0.0 & 41 & 0.0 & 0.1 & NS \\
\hline Emergency visits & 40 & 0.3 & 0.6 & 39 & 0.4 & 0.7 & NS \\
\hline Hospitalization & 40 & 0.0 & 0.0 & 37 & 0.0 & 0.0 & NS \\
\hline Adverse drug reactions, $\mathrm{n}(\%)$ & 39 & 7 & $(17.9)$ & 38 & 8 & $(21.1)$ & NS \\
\hline
\end{tabular}

Notes: aRescue medication (ATC: N02, M0I, R06). *Level of significance 0.05 (between-group comparison, unpaired $t$-test, Mann-Whitney test, Fisher's exact test). Level of significance 0.05 (within-group comparison, paired t-test, Wilcoxon signed-rank test).

Abbreviations: ATC/DDD, anatomical therapeutic classification/defined daily dose; NS, nonsignificant.

Table 5 Comparison of mean baseline and overall costs after a 3-month acupuncture treatment and a 6-month follow-up

\begin{tabular}{|c|c|c|c|c|c|c|c|c|}
\hline & \multicolumn{3}{|c|}{$\begin{array}{l}\text { Acupuncture group } \\
(\mathrm{N}=42) \text {, cost per patient }\end{array}$} & \multicolumn{3}{|c|}{$\begin{array}{l}\text { Control group }(\mathrm{N}=44) \text {, } \\
\text { cost per patient }\end{array}$} & \multirow{2}{*}{$\begin{array}{l}\text { Bootstrap t } \\
P \text {-value } \\
\text { (one tailed) } \\
P \text {-value }\end{array}$} & \multirow[b]{2}{*}{$\begin{array}{l}\text { Mean }_{\text {control }}- \\
\text { Mean }_{\text {acup }}\end{array}$} \\
\hline & $\mathbf{N}$ & Mean & $95 \% \mathrm{Cl}$ & $\mathbf{N}$ & Mean & $95 \% \mathrm{Cl}$ & & \\
\hline \multicolumn{9}{|c|}{ Baseline year } \\
\hline \multicolumn{9}{|l|}{ Direct costs } \\
\hline Medication reimbursement & 42 & 8.6 & $(2.8,14.4)$ & 44 & 16.4 & $(0.4,32.4)$ & 0.89 & 7.8 \\
\hline Medication co-payment & 42 & 9.8 & $(3.8,16)$ & 44 & 5.5 & $(2.2,8.8)$ & 0.89 & -4.3 \\
\hline Outpatient visits & 42 & 5.0 & $(4,6)$ & 44 & 4.6 & $(3.7,5.6)$ & 0.71 & -0.4 \\
\hline Emergency visits & 42 & 6.4 & $(3.5,9.2)$ & 44 & 5.7 & $(2.6,8.6)$ & 0.64 & -0.7 \\
\hline Adverse drug reactions & 42 & 0.6 & $(-0.5,1.8)$ & 44 & 0.2 & $(-0.1,0.6)$ & 0.74 & -0.3 \\
\hline Travel costs & 42 & 7.5 & $(4.3,10.9)$ & 44 & 6.8 & $(3.6,9.9)$ & 0.62 & -0.7 \\
\hline Direct total costs & 42 & 38.1 & $(-27.8,65.2)$ & 44 & 39.4 & $(19.8,58.7)$ & 0.45 & 1.2 \\
\hline \multicolumn{9}{|l|}{ Indirect costs } \\
\hline Productivity loss & 42 & 128.3 & $(57.2,199.9)$ & 44 & 249.2 & $(68,430.7)$ & 0.24 & 120.9 \\
\hline Loss of income & 42 & 6.0 & $(-2.8,15.5)$ & 44 & 4.1 & $(-2.1,10.3)$ & 0.65 & -1.9 \\
\hline
\end{tabular}


Table 5 (Continued)

\begin{tabular}{|c|c|c|c|c|c|c|c|c|}
\hline & \multicolumn{3}{|c|}{$\begin{array}{l}\text { Acupuncture group } \\
(\mathrm{N}=42) \text {, cost per patient }\end{array}$} & \multicolumn{3}{|c|}{$\begin{array}{l}\text { Control group }(\mathrm{N}=44) \text {, } \\
\text { cost per patient }\end{array}$} & \multirow{2}{*}{$\begin{array}{l}\text { Bootstrap t } \\
\text { P-value } \\
\text { (one tailed) }\end{array}$} & \multirow[b]{2}{*}{$\begin{array}{l}\text { Mean }_{\text {control }}- \\
\text { Mean }_{\text {acup }}\end{array}$} \\
\hline & $\mathbf{N}$ & Mean & $95 \% \mathrm{Cl}$ & $\mathbf{N}$ & Mean & $95 \% \mathrm{Cl}$ & & \\
\hline Indirect total costs & 42 & 134.3 & $(61.1,208.7)$ & 44 & 253.4 & $(70.9,439.9)$ & 0.27 & 119.0 \\
\hline Total costs & 42 & 172.5 & $(100.4,282.2)$ & 44 & 292.8 & $(110.8,474.4)$ & 0.26 & 120.3 \\
\hline \multicolumn{9}{|c|}{ Acupuncture treatment (3 months) } \\
\hline \multicolumn{9}{|l|}{ Direct costs } \\
\hline Medication reimbursement & 42 & 15.8 & $(5.4,27)$ & 44 & 41.5 & $(-2.0,84.3)$ & 0.12 & 25.6 \\
\hline Medication co-payment & 42 & 21.8 & $(5.9,37.7)$ & 44 & II.I & $(4.7,17.8)$ & 0.89 & -10.7 \\
\hline Acupuncture visits, patients & 42 & 308.5 & $(304.8,312.1)$ & & & & & \\
\hline Acupuncture visits, third-party payer & 42 & 25.1 & $(25.1,25.1)$ & & & & & \\
\hline Travel acupuncture costs & 42 & 120.8 & $(84.9,155.5)$ & & & & & \\
\hline Outpatient visits & 42 & 4.0 & $(2.6,5.2)$ & 44 & 4.1 & $(3.1,5.1)$ & 0.45 & 0.1 \\
\hline Travel costs & 42 & 7.8 & $(4,11.8)$ & 44 & 3.7 & $(2.2,5.2)$ & 0.97 & -4.1 \\
\hline Emergency visits & 42 & 1.8 & $(0,3.9)$ & 44 & 2.9 & $(I . I, 4.8)$ & 0.20 & I.I \\
\hline Adverse drug reactions & 42 & 0.4 & $(-0.4,1.2)$ & 44 & 0.9 & $(-0.1,1.9)$ & 0.24 & 0.4 \\
\hline Direct total costs (with acupuncture costs) & 42 & 506.4 & $(463.7,548.9)$ & 44 & 64.4 & $(20.7,108.2)$ & 0.13 & -441.9 \\
\hline Direct total costs (without acupuncture costs) & 42 & 51.9 & $(29.1,74)$ & 44 & 64.4 & $(24,105.6)$ & 0.30 & 12.5 \\
\hline \multicolumn{9}{|l|}{ Indirect costs } \\
\hline Loss of income (acupuncture) & 42 & 12.3 & $(0.1,24.9)$ & & & & & \\
\hline Productivity loss (acupuncture) & 42 & 39.9 & $(20.3,60.2)$ & & & & & \\
\hline Loss of income & 42 & 14.0 & $(-12.5,39.9)$ & 44 & 4.0 & $(-2.3,10.4)$ & 0.76 & -10.0 \\
\hline Productivity loss & 42 & 123.3 & $(-19.1,271.1)$ & 44 & 216.3 & $(-1.4,445.1)$ & 0.24 & 92.9 \\
\hline Indirect total costs (with acupuncture costs) & 42 & 189.7 & $(245 . I, 564.3)$ & 44 & 220.3 & $(-6.6,452.1)$ & 0.90 & 30.6 \\
\hline $\begin{array}{l}\text { Indirect total costs (without } \\
\text { acupuncture costs) }\end{array}$ & 42 & I37.4 & $(-2.1,275.9)$ & 44 & 220.3 & $(-1.7,449.4)$ & 0.26 & 82.9 \\
\hline Total costs (with acupuncture costs) & 42 & 696.1 & $(737.4,1,085.4)$ & 44 & 284.7 & $(32.9,523.7)$ & 0.26 & -411.3 \\
\hline Total costs (without acupuncture costs) & 42 & 189.3 & $(44.1,334.4)$ & 44 & 284.7 & $(34,533.9)$ & 0.25 & 95.4 \\
\hline \multicolumn{9}{|c|}{ 6-month follow-up } \\
\hline \multicolumn{9}{|l|}{ Direct costs } \\
\hline Medication reimbursement & 42 & 15.5 & $(6.6,24.3)$ & 44 & 44.8 & $(-5.8,94.6)$ & 0.12 & 29.3 \\
\hline Medication co-payment & 42 & 20.7 & $(2.9,39)$ & 44 & 12.0 & $(4.1,19.7)$ & 0.81 & -8.6 \\
\hline Outpatient visits & 42 & 3.2 & $(2.2,4.2)$ & 44 & 3.7 & $(2.6,4.9)$ & 0.25 & 0.5 \\
\hline Emergency visits & 42 & 4.2 & $(I . I, 7.4)$ & 44 & 6.1 & $(2.3,9.6)$ & 0.22 & 1.8 \\
\hline Adverse drug reactions & 42 & 0.1 & $(-0.1,0.5)$ & 44 & 0.3 & $(-0.3,1.1)$ & 0.28 & 0.2 \\
\hline Travel costs & 42 & 7.7 & $(2.2,2)$ & 44 & 4.6 & $(1.8,0.0295)$ & 0.86 & -3.1 \\
\hline Direct total costs & 42 & 51.7 & $(28,76)$ & 44 & 71.9 & $(21.8,124.4)$ & 0.23 & 20.1 \\
\hline \multicolumn{9}{|l|}{ Indirect costs } \\
\hline Loss of income & 42 & 3.6 & $(-3,10.2)$ & 44 & 8.3 & $(0.5,15.9)$ & 0.18 & 4.6 \\
\hline Productivity loss & 42 & 10.2 & $(2.7,18)$ & 44 & 51.6 & $(-10.2,117.8)$ & 0.085 & $4 I .4$ \\
\hline Indirect total costs & 42 & 13.9 & $(6.6,24.3)$ & 44 & 59.9 & $(-5.8,94.6)$ & 0.075 & 46.0 \\
\hline Total costs & 42 & 65.7 & $(2.9,39)$ & 44 & 131.9 & $(4.1,19.7)$ & 0.071 & 66.2 \\
\hline
\end{tabular}

Note: Mean $_{\text {control }}-$ Mean $_{\text {acup }}$, difference between the control group and the group with acupuncture treatment. 
Table 6 Sensitivity analysis

\begin{tabular}{|c|c|c|c|c|c|}
\hline \multirow[t]{2}{*}{ Acupuncture group $\mathbf{N}=42$} & \multicolumn{2}{|c|}{ Control group $\mathrm{N}=44$} & \multicolumn{3}{|c|}{ Bootstrap t, $P$-value (one tailed) } \\
\hline & Mean & $95 \% \mathrm{Cl}$ & Mean & $95 \% \mathrm{Cl}$ & $P$-value \\
\hline Direct costs (min price of acupuncture treatment in the Czech Republic) & 398.0 & $(355.2,440.6)$ & 64.4 & $(20.7,108.2)$ & 0.999 \\
\hline Total cost (min price of acupuncture treatment in the Czech Republic) ${ }^{\mathrm{a}}$ & 805.7 & $(627,979.8)$ & 284.7 & $(32.9,523.7)$ & 0.970 \\
\hline Direct costs (max price of acupuncture treatment in the Czech Republic) & 764.9 & $(725.8,806.2)$ & 64.4 & $(20.7,108.2)$ & 0.999 \\
\hline Total cost (max price of acupuncture treatment in the Czech Republic) ${ }^{\mathrm{a}}$ & $1,172.6$ & $(1,000.9,1,346.9)$ & 284.7 & $(32.9,523.7)$ & 0.999 \\
\hline
\end{tabular}

Notes: aCosts are expressed in $2015 / 2016$ EURO and are varying from $€ I I .0$ to $€ 35.0$ (cost of acupuncture session) at $0 \%$ discount rate.

visits, as well as adverse drug reactions, were nearly constant in both groups over time.

\section{Patient's perspective}

From patient's perspective, the essential costs involve the costs for acupuncture therapy ( $€ 308.5$ on average), the travel expenses related to treatment ( $€ 120.8$, on average), and the loss of income, which was monitored separately for AG and not in the CG, thus increasing the direct costs in the AG substantially. Other travel costs and medication co-payment, in absolute values, also are slightly higher in the AG, both during the acupuncture treatment period and at the 6-month follow-up. Loss of income is slightly higher in the AG as well but only within the acupuncture treatment period, in the 6-month follow-up these costs are lower.

\section{Societal perspective}

From society's perspective, it is clear that the AG shows a lower productivity lost, representing $€ 92.9$ during the acupuncture treatment period and $€ 41.4$ at the 6-month follow-up. In this regard, it is a positive phenomenon from a societal viewpoint, although the difference in values is not significant.

\section{Sensitivity analysis}

There was no significant difference between AG and CG (Table 6). Changes could be observed only in the absolute cost values.

\section{Discussion}

The present study compares the costs of acupuncture treatment in addition to standard care in patients with migraine after a 3-month course and a 6-month follow-up, considering the perspectives of a third-party payer, the patient, and the society. No significant differences in both direct and indirect costs were observed between the groups after acupuncture treatment and a 6-month follow-up. Nevertheless, it can be stated that AG presented lower costs for productivity losses and total indirect costs in comparison with the standard pharmacologic therapy at all time periods. As far as total direct costs are concerned, during the acupuncture treatment period they were higher in the AG, as it was significantly influenced by the inclusion of acupuncture costs per session and the related travel costs. In addition, it was also a double entrance medical examination, both by an internal medicine doctor and an acupuncture specialist, which is a specific feature of the Faculty Hospital Hradec Kralove. The study, nevertheless, points out a potential trend in decreased direct costs in connection with reductions in medication intake, adverse drug reactions, and ER visits by patients who took acupuncture sessions. However, further study in this respect is needed.

Similar trends have been described in other studies as well; a review by Ambrósio et a ${ }^{10}$ evaluated seven costutility and one cost-effectiveness analyses of acupuncture in the treatment of chronic pain. The conditions treated included low back pain, neck pain, dysmenorrhea, migraine and headache, and osteoarthritis. Only one cost-effectiveness study indicated that there might be both clinical benefits and cost savings associated with acupuncture when concerning migraine; ${ }^{28}$ however, another six studies indicated that the costs of acupuncture treatment are higher. Notwithstanding, a systematic review by Kim et $\mathrm{al}^{9}$ looking at economic evaluations, including cost-effectiveness, cost-utility, and cost-benefit analyses, alongside randomized controlled trials assess the consequences and costs of acupuncture for any medical condition. The cost-effectiveness analysis proved acupuncture to be beneficial at a relatively low cost in six European and Asian studies. However, only one of these studies focused on migraine, demonstrating a positive financial effect on patients in migraine treatment. ${ }^{28}$ The cost estimates in this study included acupuncture, physician visits, hospital stays, prescription medications, and the patients' incapacity to work. Deng et al ${ }^{11}$ evaluated different types of economic evaluations for acupuncture treatments for migraine in China. The data were obtained from 
a multicenter, randomized controlled trial of acupuncture treatment in patients with migraine. Four-hundred eighty migraineurs were randomly assigned to three branches of treatments with true acupoints. Treatments using specific acupoints in Shaoyang meridians are more cost-effective than that of non-acupoints, representing a dramatic improvement in the quality of life of people with migraine and a significant reduction in costs.

The majority of the above-mentioned studies, including the present one, have concluded that although acupuncture increases health care costs the additional cost can be justified by the associated short- and long-term improvements in clinical outcomes. A study by Wonderling suggested the consideration of acupuncture as a viable intervention for migraine prophylaxis because it was shown to be a cost-effective therapy, relative to a number of interventions recommended by the National Institute for Health and Care Excellence, which are provided by the National Health Service system. ${ }^{29}$ Such conclusion was also reached by Witt et al in the case of patients with primary headache where acupuncture was shown to be a cost-effective treatment according to international cost-effectiveness threshold values. ${ }^{30}$

The present study was limited by the absence of a doubleblinded method and a small sample size. On the other hand, an advantage of the study is the prospective evaluation of short- and long-term costs alongside a randomized controlled clinical trial. The present study also examined more items involved in direct and indirect costs when compared to the above-mentioned studies. For instance, in comparison with the studies from the review by Ambrósio et al, ${ }^{10}$ our study provides additional data on emergency visits, adverse drug reactions, travel costs, productivity loss, and loss of income. In addition, both direct and indirect costs were analyzed from all three viewpoints, that is, those of the patient, a third-party payer, and of society. In conclusion, a 3-month acupuncture course resulted in significant short- and long-term clinical benefits, while it suggested that acupuncture could be a financially attractive treatment option in a longer term, particularly in the case of indirect costs when compared with the absolute values of direct costs. This trend was observed also at a 6-month follow-up, although it was not significant. In the context of what has been hitherto known from the literature about the cost-effectiveness of acupuncture in migraine prophylaxis, the integration of acupuncture into health care is beneficial for society primarily when concerning lower productivity loss and loss of income, which exceed the costs of acupuncture alone. It is, therefore, reasonable to recommend acupuncture as an adjuvant treatment to the standard pharmacologic therapy in migraine prophylaxis.

\section{Acknowledgments}

The authors thank Professor Bohuslav Manek and Doctor Daniel Diaz for translation and proofreading our manuscript and Marketa Talackova for collection of medication pharmacy retail prices. This work was supported by the project (Ministry of Health, Czech Republic) for conceptual development of research organization 00179906 (MH CZ - DRO; grant number UHHK, 00179906).

\section{Disclosure}

The authors report no conflicts of interest in this work.

\section{References}

1. Steiner TJ, Stovner LJ, Birbeck GL. Migraine: the seventh disabler. Cephalalgia. 2013;33(5):289-290.

2. Diluca M, Olesen J. The cost of brain diseases: a burden or a challenge? Neuron. 2014;82(6):1205-1208.

3. WHO. Fact sheet: Headache disorders. Available from: http://www. who.int/mediacentre/factsheets/fs277/en/. Accessed September 23, 2018.

4. Linde K, Allais G, Brinkhaus B, et al. Acupuncture for the prevention of episodic migraine. Cochrane Database Syst Rev. 2016;6(6): CD001218.

5. Coeytaux RR, Befus D. Role of acupuncture in the treatment or prevention of migraine, tension-type headache, or chronic headache disorders. Headache. 2016;56(7):1238-1240.

6. Kim MR, Shin JS, Lee J, et al. Safety of acupuncture and pharmacopuncture in 80,523 musculoskeletal disorder patients: a retrospective review of internal safety inspection and electronic medical records. Medicine. 2016;95(18):e3635.

7. Zhang J, Shang H, Gao X, Ernst E. Acupuncture-related adverse events: a systematic review of the Chinese literature. Bull World Health Organ. 2010;88(12):915-921.

8. Macpherson H, Vertosick EA, Foster NE, et al. The persistence of the effects of acupuncture after a course of treatment: a meta-analysis of patients with chronic pain. Pain. 2017;158(5):784-793.

9. Kim SY, Lee H, Chae Y, Park HJ, Lee H. A systematic review of cost-effectiveness analyses alongside randomised controlled trials of acupuncture. Acupunct Med. 2012;30(4):273-285.

10. Ambrósio EM, Bloor K, Macpherson H. Costs and consequences of acupuncture as a treatment for chronic pain: a systematic review of economic evaluations conducted alongside randomised controlled trials. Complement Ther Med. 2012;20(5):364-374.

11. Deng ZQ, Zheng H, Zhao L, et al. Health economic evaluation of acupuncture along meridians for treating migraine in China: results from a randomized controlled trial. BMC Complement Altern Med. 2012;12:75

12. Evers S, Afra J, Frese A, et al; Members of the task force. EFNS guideline on the drug treatment of migraine - report of an EFNS task force. Eur J Neurol. 2006;13(6):560-572.

13. Musil F, Pokladnikova J, Pavelek Z, et al. Acupuncture in migraine prophylaxis in Czech patients: an open-label randomized controlled trial. Neuropsychiatr Dis Treat. 2018;14:1221-1228.

14. Headache Classification Subcommittee of the International Headache Society (IHS). The international classification of headache disorders 3rd edition. Cephalagia. 2013;33:629-808. 
15. Stewart WF, Lipton RB, Dowson AJ, Sawyer J. Development and testing of the Migraine Disability Assessment (MIDAS) Questionnaire to assess headache-related disability. Neurology. 2001;56(6 Suppl 1): S20-S28.

16. Drummond MF, O'Brien BJ, Stoddart GL. Method for the Economic Evaluation of Healthcare Programmes. Oxford, UK: Oxford University Press; 1997.

17. Liljas B. How to calculate indirect costs in economic evaluations. Pharmacoeconomics. 1998;13(1 Pt 1):1-7.

18. Wimo A, Reed CC, Dodel R, et al. The GERAS Study: a prospective observational study of costs and resource use in community dwellers with Alzheimer's disease in three European countries - study design and baseline findings. $J$ Alzheimers Dis. 2013;36(2):385-399.

19. Pokladnikova J, Krcmova I, Vlcek J. Economic evaluation of sublingual vs subcutaneous allergen immunotherapy. Ann Allergy Asthma Immunol. 2008;100(5):482-489.

20. Maresova P, Klimova B, Novotny M, Kuca K. Alzheimer's and Parkinson's diseases: expected economic impact on Europe-a call for a uniform European strategy. J Alzheimers Dis. 2016;54(3): 1123-1133.

21. WHO Collaborating Centre for Drug Statistics Methodology. ATC/ DDD Index 2017. Available from: https://www.whocc.no/atc_ddd_ index/. Accessed September 23, 2018.

22. General Health Insurance Fund of the Czech Republic. Available from: https:/www.vzp.cz/poskytovatele/ciselniky/zdravotni-vykony. Accessed September 23, 2018
23. General Health Insurance Fund of the Czech Republic. Available from: https://www.vzp.cz/poskytovatele/ciselniky/hromadne-vyrabenelecive-pripravky-a-potraviny-pro-zvlastni-lekarske-ucely/archiv. Accessed September 23, 2018.

24. Ministry of Labour and Social Affairs of the Czech Republic. Available from: http://www.mpsv.cz/cs/78. Accessed September 23, 2018.

25. CSU. Czech Statistical Office. Available from: https://www.czso.cz/csu/ czso/makroekonomika-fqhqlzbynt. Accessed September 23, 2018.

26. CSU. Czech Statistical Office. Available from: http://www.czso.cz/csu/ redakce.nsf/i/tab_2_ekonomika_a_infrastruktura_zu/\$File/2zu_eki.xls. Accessed September 23, 2018.

27. Heyse J, Cook J, Carides G. Statistical considerations in analysing healthcare resource utilization and cost data. In: Drummond M, McGuire A, editors. Economic Evaluation in Healthcare: Merging Theory with Practice. New York, NY: Oxford University Press; 2001: 215-235.

28. Liguori A, Petti F, Bangrazi A, et al. Comparison of pharmacological treatment versus acupuncture treatment for migraine without auraanalysis of socio-medical parameters. J Tradit Chin Med. 2000; 20(3):231-240.

29. Wonderling D, Vickers AJ, Grieve R, Mccarney R. Cost effectiveness analysis of a randomised trial of acupuncture for chronic headache in primary care. BMJ. 2004;328(7442):747.

30. Witt CM, Reinhold T, Jena S, Brinkhaus B, Willich SN. Cost-effectiveness of acupuncture treatment in patients with headache. Cephalalgia. 2008;28(4):334-345.
Neuropsychiatric Disease and Treatment

\section{Publish your work in this journal}

Neuropsychiatric Disease and Treatment is an international, peerreviewed journal of clinical therapeutics and pharmacology focusing on concise rapid reporting of clinical or pre-clinical studies on a range of neuropsychiatric and neurological disorders. This journal is indexed on PubMed Central, the 'PsycINFO' database and CAS,

\section{Dovepress}

and is the official journal of The International Neuropsychiatric Association (INA). The manuscript management system is completely online and includes a very quick and fair peer-review system, which is all easy to use. Visit http://www.dovepress.com/testimonials.php to read real quotes from published authors. 